\title{
Medicine in Extreme Environments: A New Medical Student Elective Class for Wilderness, Aerospace, Hyperbaric, Exercise, and Combat Medicine
}

\author{
Gautam Babu, BA ${ }^{1,2}$; Bradley D. Upchurch, $\mathrm{BS}^{2}$; William H. Young, BS ${ }^{2}$; Benjamin D. Levine, $\mathrm{MD}^{1,3}$ \\ ${ }^{1}$ Institute for Exercise and Environmental Medicine, Texas Health Presbyterian Dallas, Dallas, TX; ${ }^{2}$ UT Southwestern Medical School, UT Southwestern \\ Medical Center, Dallas, TX; ${ }^{3}$ Department of Internal Medicine, UT Southwestern Medical Center, Dallas, TX
}

\begin{abstract}
We developed an elective course titled Medicine in Extreme Environments (MEE) at the University of Texas Southwestern Medical Center for first- and second-year medical students. This course covered physiology, research, clinical practice, and career guidance regarding the fields of wilderness, space, hyperbaric, combat, and exercise medicine. The primary aim was to generate interest in and awareness of these seldom covered fields of medicine by exposing medical students to these disciplines during their preclinical years. A postcourse questionnaire was implemented to investigate whether the MEE course increased awareness of, interest in, and knowledge in the fields of medicine included in the curriculum. Through 2 iterations of the class, a total of 67 students enrolled in the course, and 38 students completed the questionnaire. After course completion, $95 \%$ felt they better understood the work and lifestyle of the fields covered, $100 \%$ learned more about concepts of each field, and 74\% agreed that the elective influenced the direction of their future careers to include some part of the fields emphasized. Although only a limited number of students enrolled in this course, these initial findings suggest that the MEE curriculum may have some utility in promoting awareness of and interest in these medical disciplines among students who attend the course. With continued student and faculty support, this course will likely be continued annually at our institution. We believe that certain aspects of this course may be useful in helping develop similar courses at other medical schools.
\end{abstract}

Keywords: medical education, wilderness medicine, aerospace medicine, hyperbaric medicine, high altitude medicine, sports medicine

\section{Introduction}

In the course of medical education and practice, training focuses predominantly on providing care for patients in controlled and well-equipped medical environments. Much less emphasis is placed on the issues faced by individuals in "extreme environments," which are situations in which individuals are exposed to environmental elements (eg, extreme temperatures, changes in atmospheric pressure, or microgravity) that alter the management of medical conditions. Although there are residency and fellowship

Corresponding author: Gautam Babu, BA, Institute for Exercise and Environmental Medicine, Texas Health Presbyterian Hospital Dallas, 7232 Greenville Avenue, Suite 435, Dallas, TX 75231; e-mail: Gautam.Babu.16@Dartmouth.edu.

Submitted for publication March 2019.

Accepted for publication October 2019. programs dedicated to practicing in these environments, medical students may only receive limited preclinical exposure to them. While medical schools across the country and abroad offer student-run wilderness medicine interest groups, wilderness medicine workshops, away rotations in wilderness medicine through the visiting student application service, and electives in wilderness medicine, ${ }^{1-7}$ there has not been a published curriculum for a preclerkship elective. We believe that it is beneficial to create a curriculum that synthesizes research, pathophysiology, career guidance, and practical medical applications not only from the field of wilderness medicine but also in related fields that practice in their own "extreme environments." These types of experiences offer medical students the opportunity to learn about these other disciplines in which they could potentially practice and research. ${ }^{8}$ Providing this curriculum during the preclinical years of medical school may 
encourage students to plan and pursue the postgraduate training necessary to participate in their field of interest.

To address the lack of a published curriculum regarding a preclerkship course focused on exposure to "extreme environments," we describe our curriculum for a 3-mo elective course titled Medicine in Extreme Environments (MEE). This course was a student-driven initiative with faculty support at the University of Texas Southwestern Medical School and was designed for first- and secondyear medical students. Our class objectives included introducing students to the topics of wilderness, aerospace, high altitude, hyperbaric, exercise, and combat medicine, as well as increasing students' knowledge of physiology, research, and clinical practice within these fields. Additional dimensions to this class included career guidance provided by class instructors from sites across the country with expertise in each individual field. To investigate whether the MEE course increased awareness of, interest in, and knowledge in the fields of medicine included in the curriculum, a postcourse questionnaire was administered. This publication describes the framework, development, and objectives of our elective, as well as the survey results used to evaluate the course.

\section{Methods}

\section{CURRICULUM DEVELOPMENT}

We used UT Southwestern's pre-existing structure for preclinical noncredit enrichment electives, which allowed students to explore topics such as medical ethics, medical law, medical finance, and global health through seminars and small group discussions. Medical students are permitted to develop new electives that can be offered to all students at UT Southwestern provided that their class proposal has a faculty sponsor, includes a minimum of 12 instructional hours, and has a comprehensive course syllabus. Once the elective proposal is approved by the enrichment elective committee, the office of medical education formally includes the class in the online registration portal. In addition to the enrichment elective requirements, we established our curriculum based on the methods described in Curriculum Development for Medical Education: A Six-Step Approach. ${ }^{9}$ We chose class topics based on input from medical school faculty members with expertise in fields of medicine related to "extreme environments" to fulfill our class objectives. We also covered material deemed essential for wilderness medical student electives. ${ }^{7}$

In addition to an introductory class, there were 6 standard 1-h lecture experiences covering space physiology, psychological impact of isolated environments, high altitude medicine, combat medicine, heat stress during exercise, and chronic traumatic encephalopathy in sports. The
5 remaining instructional hours were structured as interactive learning experiences. The wilderness medicine workshop consisted of a didactic lecture followed by experiential learning, which included training for techniques such as the construction and placement of splints, sling placement, and tourniquet use. Another class involved a tour of a hyperbaric chamber and exercise physiology laboratory combined with a lecture on hyperbaric medicine. The final class was a student-led journal club designed to parallel the root cause analysis concept behind medical morbidity and mortality conferences. The students were split into groups of 4 and encouraged to research, analyze, and present interesting cases involving deaths or injuries in "extreme environments." Last, during each class, all lecturers included a discussion about the career training required to enter their respective fields and their own personal journey to a successful career in each distinctive field. The course curriculum and schedule are listed in Table 1.

\section{TIMING}

The course was offered at 2 times: spring 2018 and fall 2018. After reviewing the medical student preclinical schedule, weekly time slots that did not interfere with mandatory activities were selected. A survey poll with the potential time slots was sent to enrolled students, and the most popular time slot was chosen based on student responses.

\section{PARTICIPANTS}

UT Southwestern's enrollment as of fall 2018 consisted of 905 medical students (approximately half of whom are first- and second- year students), 484 graduate students, and 364 health professions students (physician assistant, physical therapy, nutrition, orthotics, and prosthetics). We offered this course to UT Southwestern first- and secondyear medical students, graduate students, and health professions students by email. However, the class schedule was arranged around mandatory activities for medical students, which made it difficult for graduate and health professions students to attend. Interested students registered on a firstcome first-served basis with a cap set at 35 students per UT Southwestern policy. Thirty-two students enrolled in the class (30 medical students, 2 physician assistant students) during the first iteration, and 35 students (all medical students) enrolled during the second iteration.

\section{QUESTIONNAIRES}

Questionnaires were used to investigate whether the MEE course would improve awareness of, interest in, and knowledge in fields of medicine included in the curriculum. Survey questions are shown in Table 2. 
Table 1. Medicine in Extreme Environments weekly curriculum guide

\begin{tabular}{|c|c|c|c|c|}
\hline & Lecture title & Description & $\begin{array}{l}\text { Course } \\
\text { topic }\end{array}$ & $\begin{array}{l}\text { Duration } \\
\text { (h) }\end{array}$ \\
\hline 1 & $\begin{array}{l}\text { "Medicine in Extreme Environments } \\
\text { Introduction" }\end{array}$ & $\begin{array}{l}\text { An introduction into the fields of wilderness medicine } \\
\text { emphasizing membership, research, and postgraduate } \\
\text { opportunities. The clinical presentation and management } \\
\text { of acute mountain sickness was also discussed during the } \\
\text { second half of the class. }\end{array}$ & $\begin{array}{l}\text { High } \\
\text { Altitude } \\
\text { Medicine }\end{array}$ & 1 \\
\hline 2 & $\begin{array}{l}\text { "Climbing the Seven Summits: } \\
\text { Physiology, Pathophysiology, and Life } \\
\text { Lessons Learned" }\end{array}$ & $\begin{array}{l}\text { An autobiographical account describing the experiences } \\
\text { of climbing the highest peak on every continent while } \\
\text { concurrently teaching the physiological homeostatic } \\
\text { mechanisms to high altitude. }\end{array}$ & $\begin{array}{l}\text { High } \\
\text { Altitude } \\
\text { Medicine }\end{array}$ & 1 \\
\hline 3 & $\begin{array}{l}\text { "General Considerations for } \\
\text { Spaceflight" }\end{array}$ & $\begin{array}{l}\text { A lecture on the cardiovascular, neurological, and } \\
\text { musculoskeletal changes that occur secondary to the } \\
\text { microgravity environment; current International Space } \\
\text { Station countermeasures for these issues were also } \\
\text { discussed. }\end{array}$ & $\begin{array}{l}\text { Aerospace } \\
\text { Medicine }\end{array}$ & 1 \\
\hline 4 & "Psychology of Isolated Environments" & $\begin{array}{l}\text { An in-depth description and analysis of the psychiatric } \\
\text { implications for space missions (specifically } \\
\text { considerations for a trip to Mars) and other prolonged } \\
\text { expeditions. Careers related to space medicine were also } \\
\text { discussed. }\end{array}$ & $\begin{array}{l}\text { Aerospace } \\
\text { Medicine }\end{array}$ & 1 \\
\hline 5 & $\begin{array}{l}\text { "Combat Medicine: A Review of } \\
\text { TCCC Guidelines and MARCH } \\
\text { Algorithm" }\end{array}$ & $\begin{array}{l}\text { A review of combat medicine training and careers, with a } \\
\text { discussion on the approach to common critical care } \\
\text { scenarios within combat/trauma settings. }\end{array}$ & $\begin{array}{l}\text { Combat } \\
\text { Medicine }\end{array}$ & 1 \\
\hline 6 & $\begin{array}{l}\text { "Deep Diving and Hyperbaric } \\
\text { Medicine" }\end{array}$ & $\begin{array}{l}\text { A presentation focused on the physiological changes in } \\
\text { deep diving, the clinical utility of hyperbaric chambers, } \\
\text { and pathway to a career in hyperbaric medicine. This } \\
\text { experience also included a tour of a hyperbaric chamber } \\
\text { and exercise physiology laboratory. }\end{array}$ & $\begin{array}{l}\text { Hyperbaric } \\
\text { Medicine }\end{array}$ & 2 \\
\hline 7 & $\begin{array}{l}\text { "Concussions and CTE: Evolution of } \\
\text { NFL Concussion Policy" }\end{array}$ & $\begin{array}{l}\text { A discussion on the mechanisms behind concussions and } \\
\text { chronic traumatic encephalopathy, National Football } \\
\text { League concussion policies and player safety, and the } \\
\text { strategies that have been implemented to reduce the rate of } \\
\text { concussions across all levels of football. }\end{array}$ & $\begin{array}{l}\text { Sports } \\
\text { Medicine }\end{array}$ & 1 \\
\hline 8 & $\begin{array}{l}\text { "Thermal Stress and Hot } \\
\text { Environments" }\end{array}$ & $\begin{array}{l}\text { An introduction to the physiologic adaptations to heat } \\
\text { stress, along with the treatment and prevention strategies } \\
\text { for common heat-related illnesses. }\end{array}$ & $\begin{array}{l}\text { Sports } \\
\text { Medicine }\end{array}$ & 1 \\
\hline 9 & "Practical Wilderness Medicine" & $\begin{array}{l}\text { A discussion on the diagnosis, treatment, and prevention } \\
\text { of the most common wilderness injuries, along with } \\
\text { hands-on experience practicing techniques in stabilizing } \\
\text { injured patients in remote settings. }\end{array}$ & $\begin{array}{l}\text { Wilderness } \\
\text { Medicine }\end{array}$ & 2 \\
\hline 10 & $\begin{array}{l}\text { "What Went Wrong?: Common } \\
\text { Wilderness Scenarios" }\end{array}$ & $\begin{array}{l}\text { A student-led "M\&M conference-like" experience } \\
\text { wherein students researched high-profile deaths/injuries in } \\
\text { extreme environments. Students described the } \\
\text { physiological process that led to the patient's death/injury } \\
\text { and proposed ways to prevent the recurrence of these } \\
\text { types of events. }\end{array}$ & $\begin{array}{l}\text { Wilderness } \\
\text { Medicine }\end{array}$ & 1 \\
\hline
\end{tabular}


Table 2. Responses to postcourse student satisfaction surveys from both iterations of the course

\begin{tabular}{|c|c|c|c|c|c|c|c|c|}
\hline Question & $S A$ & $A$ & $N$ & $D$ & $S D$ & $\begin{array}{l}\text { Responses } \\
(n)\end{array}$ & $\begin{array}{l}S A / A \\
(\%)\end{array}$ & $\begin{array}{l}S D / D \\
(\%)\end{array}$ \\
\hline The course met the learning objectives stated in the syllabus. & 20 & 17 & 1 & 0 & 0 & 38 & 97 & 0 \\
\hline The clinical relevance of the course material was apparent. & 19 & 14 & 1 & 4 & 0 & 38 & 87 & 11 \\
\hline The course improved my understanding of human physiology. & 17 & 19 & 0 & 1 & 1 & 38 & 95 & 5 \\
\hline $\begin{array}{l}\text { The course improved my knowledge of less well-known fields of medicine } \\
\text { (aerospace, hyperbaric, wilderness, high altitude). }\end{array}$ & 25 & 13 & 0 & 0 & 0 & 38 & 100 & 0 \\
\hline $\begin{array}{l}\text { The course influenced/altered my potential future career interests in medicine to } \\
\text { include areas/topics covered in the class. }\end{array}$ & 15 & 13 & 6 & 4 & 0 & 38 & 74 & 11 \\
\hline The research presented was relevant to the topics discussed in each class. & 22 & 15 & 1 & 0 & 0 & 38 & 97 & 0 \\
\hline $\begin{array}{l}\text { The research presented gave me a better understanding of the type of work that is } \\
\text { done in those medical fields. }\end{array}$ & 23 & 13 & 2 & 0 & 0 & 38 & 95 & 0 \\
\hline $\begin{array}{l}\text { The wilderness medicine workshop caused me to be better equipped to deal with } \\
\text { common wilderness emergencies. }\end{array}$ & 23 & 12 & 2 & 0 & 0 & 37 & 95 & 0 \\
\hline
\end{tabular}

$\mathrm{SA}$, strongly agree; A, agree; $\mathrm{N}$, neutral; $\mathrm{D}$, disagree; $\mathrm{SD}$, strongly disagree, $\mathrm{SA} / \mathrm{A}(\%)$, percent of students who strongly agree or agree; $\mathrm{SD} / \mathrm{D}(\%)$, percent of students who strongly disagree or disagree.

In addition to the postcourse satisfaction survey, students in the second iteration of the class were given a precourse and postcourse test to assess their knowledge before and after the course. The test consisted of 9 questions aiming to emphasize an important concept in each individual class. The same 9 questions were used for both the pretest and posttest. Only students in the second iteration who attended greater than $60 \%$ of classes were given the postcourse knowledge test. Scores are presented as mean \pm SD.

\section{ETHICAL APPROVAL}

The UT Southwestern human research protection program determined the study was "nonregulated research" and therefore did not require institutional review board approval or oversight.

\section{STATISTICS}

We used $t$ tests for repeated measures to investigate the differences between students' scores on the precourse and postcourse tests. Statistical significance was set to $P<0.05$.

\section{Results}

For the first iteration of the class, 16 of the total 32 enrolled students completed the survey; 22 of 35 enrolled students completed the survey during the second iteration. Many of the students who initially enrolled in the course simply attended the first class and did not return for further classes; hence, they were not given the end-of-course survey. Results of the 38 postcourse satisfaction surveys from both iterations were aggregated. After completion of this course, $100 \%$ of students strongly agreed or agreed that the class improved their knowledge of low-exposure medical fields. Similarly, 95\% believed that the research presented in the class gave them a better understanding of the type of work done in those disciplines. Furthermore, following course participation, $74 \%$ of students agreed that the elective influenced or altered the direction and focus of their future medical careers to include some part of the low-exposure fields emphasized. There was also a strong sentiment (95\% of students) that the course improved students' understanding of human physiology after course completion. Responses to key survey questions are shown in Table 2. Finally, nearly all respondents (92\% or greater) were satisfied with course structure and content, found faculty teaching effective, and would recommend the class to future students.

Of the 35 students enrolled in the second iteration, only 17 had an attendance record of greater than $60 \%$ and were given the precourse and postcourse test. The precourse test score was $35 \pm 20 \%$, and the postcourse test score was $59 \pm 13 \%(P=0.0004)$ (Table 3$)$. Performance on each individual question before and after the course is also presented in Table 3. There was an increase in the class-wide percentage correct for every question, with the exception of a decrease from 94 to $82 \%$ for High Altitude Q1. The largest increase was for hyperbaric medicine, with the percentage correct increasing from 0 to $53 \%$.

\section{Discussion}

Our primary goal was to create and assess an elective course that exposes preclerkship students to disciplines of medicine related to "extreme environments" to improve awareness of, knowledge in, and interest in those fields. We investigated whether introducing MEE in the 
preclinical years would accomplish this goal by using a postcourse survey. The results of the survey suggest that students believed the course does increase their awareness and knowledge. Additionally, the majority of students felt that the course influenced them to potentially include some aspect of these fields in their future medical careers. This suggests our curriculum likely met our primary aim of exposure. The wide array of class topics and course format most likely contributed to the students' sense of exposure. Although this course presently has several notable limitations, these aspects of MEE have the potential to be used at other institutions for a similar purpose. While the curriculum does emphasize the expertise of our faculty members, the focus of the curriculum is not the specific lecture topics themselves, but rather early exposure to the variety of fields pertaining to "extreme environments." Instructors at other institutions can select different lecture topics and still provide exposure to each of these fields. Some institutions might also not have faculty members in every field discussed in this curriculum, but this can be addressed through the use of videoconference lectures. Ultimately, we believe that this type of curriculum may be able to aid in attracting medical students early in their careers to pursue fields of medicine with which they were previously unfamiliar at medical schools across the country.

Furthermore, although our course focused on exposure rather than proficiency, we sought to assess the knowledge our students gained pertaining to each individual topic as a secondary outcome. Using our precourse and postcourse assessments, we were able to see some promise in improving students' knowledge in the fields of wilderness medicine. However, the postcourse performance was still poor with regard to conventional testing standards that require $70 \%$ or above for a passing grade. Students had little incentive to study for the postcourse assessment owing to the noncredit nature of enrichment electives, which likely contributed to the poor scores recorded. The questions used may also have been too difficult or not representative of material emphasized in lectures. The limitations discussed will need to be addressed before it can be shown that students attending the course become proficient in the topics covered.

\section{LIMITATIONS}

There were several significant limitations to the assessment of our course. Most prominent is the low participation numbers and low survey response rate among those who enrolled in the class. Low enrollment is likely due to the UT Southwestern policy of capping enrichment electives and the large number of other electives in which students could enroll instead. As an optional noncredit elective, no penalty was given for poor attendance or participation in class activities, which probably led to the small number of survey 
responses among those initially enrolled. Insufficiently interesting content, presentations of inadequate quality, and inconvenient scheduling also cannot be ruled out as potential causes of decreased participation. With regard to the postcourse questionnaire, certain statements such as "The course improved my knowledge of less well-known fields of medicine" were too general, and students were unlikely to answer this question with responses other than agree or strongly agree. More focused statements such as "After course completion, I know the necessary materials to fashion a tourniquet" would have better delineated the specific areas in which students felt their knowledge improved due to MEE. Furthermore, the lack of a precourse questionnaire to assess interest in these topics prior to class participation made it difficult to assert that MEE definitively influenced students to report that their career interests now include topics discussed in the class.

The knowledge assessment had several limitations as well, most notably the small sample size; therefore, the performance results may not have been an accurate representation of the general student population. Additionally, the limited number of questions in the assessment may not have accurately encompassed all material covered in the class, and students may have been better or less prepared to respond to concepts that were not included. Finally, the questions were developed by the student coordinators rather than by the faculty members giving lectures. Although the questions were chosen from material presented by lecturers during the first course iteration, they may not appropriately target the concepts deemed most important by faculty members.

\section{FUTURE DIRECTIONS}

In future versions of the class, recording student characteristics such as age, sex, and, in particular, prior exposure to or interest in one of the disciplines discussed in the course would be informative. This information could allow us to ascertain whether students who are previously attracted to topics in the class are more inclined to become interested in related careers as compared to previously uninterested students. There will also be value in longitudinally following students who have participated in the class to assess whether they become involved in away rotations, fellowships, or careers related to "extreme environments." Course administrators will also continue to seek opportunities for hands-on learning, as student comments suggested they most enjoyed the practical experiences. A better assessment of students' knowledge before and after course completion is also necessary. We plan to use an increased number of questions and discuss with faculty the inclusion of questions with an appropriate degree of difficulty. Finally, we hope to improve retention of material discussed in classes through course handouts and increased active student participation in lecture-based classes.

\section{Conclusions}

The MEE curriculum may have utility in exposing students to wilderness medicine and increasing their career awareness of a broad range of fields. Specifically, the description of the course format and overarching topics provided here may help other institutions develop a class with a similar purpose of exposing preclinical students to "extreme environments." However, further student participation data are still needed to show the impact of a MEE-type course on preclinical students' wilderness medicine knowledge and career choices.

Acknowledgments: We acknowledge our course lecturers: Benjamin Levine, Biff Palmer, Jay Buckey, Alex Eastman, Renie Guilliod, Hunt Batjer, Craig Crandall, and Bradly Mueller; previous student liaisons, Jonathan Harder and Timothy Benage; and the UT Southwestern office of medical education for guidance, especially Dorothy Sendelbach.

Author Contributions: Study concept and design (GB, BU, WY, BL); acquisition of the data (GB, BU, WY); analysis of the data (GB, BU, WY); drafting of final manuscript (GB, BU, WY); critical revision of the manuscript (GB, BU, WY); approval of final manuscript (GB, BU, WY, $\mathrm{BL})$.

Financial/Material Support: None.

Disclosures: None.

\section{References}

1. Donelan S. Student electives in wilderness medicine: curriculum guidelines-an introduction. Wilderness Environ Med. 2014;25(4):472-3.

2. Feazel L, Block J, Jayawardena A, Wehr P, House H, Buresh C. Wilderness medicine race for preclinical students. Clin Teach. 2016;13(4):271-6.

3. Fielding CM. Introducing medical students to wilderness medicine. Wilderness Environ Med. 2011;22(1), 91-3.

4. McGraw D, Gluckman SJ. The perceived benefits of a medical school course in wilderness medicine. Wilderness Environ Med. 2005;16(2):106-10.

5. Mazoyer P, Hardern RD. Lessons learned on a wilderness medicine "teaching weekend." Wilderness Environ Med. 2011;22(3):277-80.

6. Ledrick DJ. The Medical Wilderness Adventure Race (MedWAR): a 2-year perspective on a unique learning experience. Wilderness Environ Med. 2003;14(4):273-6.

7. Lareau SA, Caudell MJ, Pandit KB, Hiestand BC. Medical student electives in wilderness medicine: curriculum guidelines. Wilderness Environ Med. 2014;25(4):474-80.

8. Lipman GS, Weichenthal L, Stuart Harris N, McIntosh SE, Cushing T, Caudell MJ, et al. Core content for wilderness medicine fellowship training of emergency medicine graduates. Acad Emerg Med. 2014;21(2):204-7.

9. Thomas PA, Kern DE, Hughes MT, Chen BY. Curriculum Development for Medical Education: A Six-Step Approach. Baltimore, MD: JHU Press; 2016. 